\title{
OPTIMIZATION AND INFLUENCE OF SOME PHYSICO-CHEMICAL PARAMETERS ON THE SYNTHESIS OF CHITOSAN-TRIPOLYPHOSPHATE NANOPARTICLES
}

\author{
IOANA-MIRELA VASINCU ${ }^{1 \#}$, LENUȚA PROFIRE $^{1}$, MARIA APOTROSOAEI ${ }^{1}$, ANCA \\ ROXANA PETROVICI ${ }^{2 \#}$, MARIANA PINTEALA ${ }^{2}$, ALEXANDRA JITĂREANU $^{3 *}$, SANDRA- $^{2}$ \\ MĂDĂLINA CONSTANTIN ${ }^{1}$
}

\author{
${ }^{1}$ Department of Pharmaceutical Chemistry, Faculty of Pharmacy, "Grigore T. Popa” University of Medicine and Pharmacy, \\ 16 Universitătii Street, 700115, Iași, Romania \\ ${ }^{2}$ Centre of Advanced Research in Bionanoconjugates and Biopolymers Department, "Petru Poni" Institute of Macromolecular \\ Chemistry, 4lA Aleea Grigore Ghica-Voda, 700487, Iaşi, Romania \\ ${ }^{3}$ Department of Toxicology, Faculty of Pharmacy, "Grigore T. Popa" University of Medicine and Pharmacy, 16 Universităţii \\ Street, 700115, Iaşi, Romania
}

*corresponding author: jitareanu.alexandra@umfiasi.ro

${ }^{*}$ Authors with equal contribution

Manuscript received: May 2019

\begin{abstract}
In the past decades, the researchers have focused their attention on the synthesis of new polymeric nanoparticles as drug delivery systems based on their small particle size and large surface area. The aim of this study was to optimize the synthesis of chitosan-based nanoparticles (CSNPs) and to study the influence of different parameters on the formulation process. The CSNPs were prepared by the ionic gelation method using sodium tripolyphosphate (TPP) as cross-linking agent and two types of chitosan (CS) (low and medium molecular weight). In order to optimize the preparation method, several parameters, such as the CS and TPP concentration, the $\mathrm{pH}$ of CS solution, the stirring speed and the reticulation time have been varied. The CSNPs synthesis was monitored by dynamic light scattering (DLS) technique. The results showed that the optimized method use $0.1 \%$ TPP and $0.1 \%$ CS low molecular weight in ratio of 3:1, with pH ranking between 4.7 and 4.8 and stirring at $1000 \mathrm{rpm}$ for $1 \mathrm{~h}$. In these conditions the size of CSNPs was $208.8 \pm 8.5 \mathrm{~nm}$ with 0.151 polydispersity index. Based on the obtained results it could be appreciated that optimized CSNPs could be further used as drug carriers.
\end{abstract}

\section{Rezumat}

În ultimele decenii, cercetătorii și-au axat atenția pe sinteza de noi nanoparticule polimerice ca sisteme de eliberare a medicamentelor, datorită dimensiunii mici a particulelor și a suprafeței mari. Scopul acestui studiu a fost optimizarea metodei de sinteză pentru nanoparticule de chitosan (CSNPs) prin studierea influentei diferitelor parametrii asupra procesului de formulare. Nanoparticulele de chitosan au fost preparate prin metoda gelificării ionice folosind tripolifosfat de sodiu (TPP) ca agent de reticulare și două tipuri de chitosan (CS) (cu greutate moleculară mică și medie). În vederea optimizării metodei de preparare, s-au modificat diferiți parametri cum ar fi concentrația de CS și TPP, pH-ul soluției de CS, viteza de agitare a amestecului și timpul de reticulare. Sinteza nanoparticulelor a fost monitorizată prin tehnica de dispersie dinamică a luminii (DLS). Rezultatele au arătat că metoda optimizată implică folosirea solutiei de TPP $0,1 \%$, de CS cu greutate moleculară mică $0,1 \%$, în raport de $3: 1$, cu un pH cuprins între 4,7 - 4,8 și viteză de agitare de 1000 rpm, timp de o oră. În aceste condiții, mărimea particulelor obținute a fost de $208,8 \pm 8,5 \mathrm{~nm}$, având un indice de polidispersie de 0,151 . Pe baza rezultatelor obținute se poate aprecia că nanoparticulele de chitosan optimizate pot fi utilizate în continuare ca sisteme de transport a medicamentelor.

Keywords: chitosan, nanoparticles, ionic gelation method, TPP

\section{Introduction}

In the last time the researchers have focused on nanotechnology, based on its important applications in different fields including drug delivery systems [19]. Using nanotechnology principles, the features of the drugs such as solubility, bioavailability, biological effects and toxicity degree were improved. One of the intensely studied nanosystems are the nanoparticles (NPs), which are frequently used due to their important advantages such as small particle size $(1-1000 \mathrm{~nm})$ [25], large ratio active surface area/volume [2], high stability, feasibility of different drugs encapsulation, high carrier capacity and efficacy [17]. The NPs proved to reduce the doses frequency, to provide the controlled and targeted release of loaded drugs and to improve the tolerability of the active substances [16]. The most important types of NPs used as drug carrier systems are polymeric biodegradable and ceramic 
nanoparticles, dendrimers, micelles and liposomes [33]. Moreover, the polymeric NPs, solid colloidal particles, with a diameter ranging between $10 \mathrm{~nm}$ and $1000 \mathrm{~nm}$, showed to be the most effective and the ideal candidates for different therapies [4, 19, 22]. The performance of these nanosystems is depending on the polymer's features such as: $\mathrm{pH}$-sensitive solubility, biodegradability, toxicity, and ability to load various drugs [18].

The chitosan (CS) is a natural polysaccharide obtained by alkaline deacetylation of shellfish chitin, being considered the largest biomaterial after cellulose $[11,14,37]$.

CS has attracted the interest of the researchers, firstly due to its unique properties: biocompatibility, biodegradability and low toxicity [7, 31] and secondly due to its improved processing [29]. Literature reports various applications of this biopolymer in pharmacy, medicine, and biotechnology fields due to its important biological effects, such as antimicrobial (antifungal, antibacterial, antiviral) antioxidant, antitumoral, hypocholesterolemiant, and hypoglicemiant $[11,20,24$, $26,28]$. In addition, CS has good adhesion to mucosal surfaces [12] and cationic character, which explain its solubility in acidic solutions [8]. With a pKa value of 6.5 , it is slightly soluble in neutral or alkaline solutions due to the deprotonation of amino groups [10]. The hydroxyl and amino reactive groups of CS allow its chemical modulation and the formation of different polyelectrolytes and ionic complexes [8, 9]. The chitosan-based nanoparticles (CSNPs) can be obtained using two different cross-linking methods: a chemical one, based on covalent bonds formation between the functional groups of the biopolymer and a physical one, reversible, based on electrostatic forces, hydrogen bonds or hydrophobic interactions between the polymer chains [1, 5, 32]. Among these methods, the researchers have focused on the ionic gelation, because it is an organic solvent free, nontoxic, and inexpensive process, which can be easily performed [13]. This technique is based on ionic interactions between the positively charged amino groups of CS and the negatively charged groups of pentasodium tripolyphosphate (TPP) (Figure 1), which is the most used cross-linking agent due to its safety and multivalent characteristics $[3,5]$.

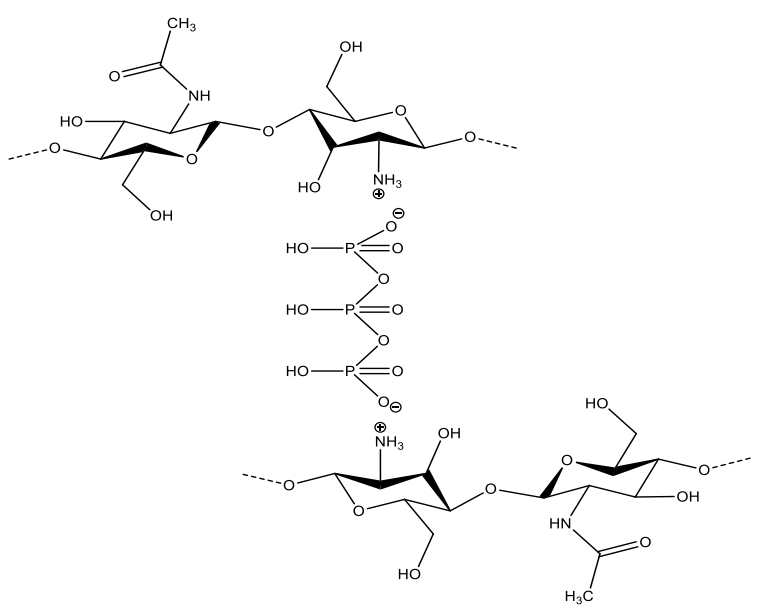

Figure 1.

The CSNPs formation by ionic gelation method [35]

\section{Materials and Methods}

Materials: Chitosan low molecular weight $\left(\mathrm{CS}_{\mathrm{LMw}}\right.$, molecular weight 50 - $190 \mathrm{kDa}, 75$ - 85\% deacetylation degree, viscosity $20-300 \mathrm{cP}$ ), chitosan medium molecular weight (CS $\mathrm{CS}_{\mathrm{Mm}}$, molecular weight 190 $310 \mathrm{kDa}, 75-85 \%$ deacetylation degree, viscosity 200 - $800 \mathrm{cP}$ ), pentasodium tripolyphosphate (TPP), acetic acid (min. $99.8 \%$, p.a. ACS reagent), sodium hydroxide $(\mathrm{NaOH})$ and Tween 80 were purchased from Sigma Aldrich.

The preparation of CSNPs

The chitosan-based nanoparticles (CSNPs) were obtained using the ionic gelation method according to the literature data with some modifications [2, $15,34,36,39]$. In order to optimize the formation of CSNPs, different weight ratio between CS (with different molecular weights) and TPP were used. The $0.1 \%$ (w/v) CS solutions were obtained by dissolving of $\mathrm{CS}\left(\mathrm{CS}_{\mathrm{LMw}}, \mathrm{CS}_{\mathrm{MMw}}\right)$ in $0.15 \%(\mathrm{w} / \mathrm{v})$ acetic acid under light stirring at room temperature overnight [13]. Then, the CS solutions were passed through a syringe filter $(0.22 \mu \mathrm{m})$ and the $\mathrm{pH}$ was measured $\left(\mathrm{CS}_{\mathrm{LMW}}\right.$ - 3.8, $\mathrm{CS}_{\mathrm{MMW}}$ - 3.7). Separately, the TPP was dissolved in distilled water to obtain a solution of $0.1 \%(w / v)$. Different volumes of $0.1 \%$ TPP were dropped into different volumes of $0.1 \% \mathrm{CS}_{\mathrm{LMW}}$ and $\mathrm{CS}_{\mathrm{Mmw}}$, under magnetic stirring, with a speed of $700 \mathrm{rpm}$. The obtained mixture was stirred for additional $60 \mathrm{~min}$, at room temperature. In order to study the influence of the concentration on CSNPs formation, several concentrations (w/v) of TPP $(0.1 \%$, $0.15 \%, 0.2 \%)$ and CS $(0.05 \%, 0.1 \%, 0.133 \%, 0.167 \%$, 
FARMACIA, 2019, Vol. 67, 6

$0.2 \%)$ were used. The influence of $\mathrm{pH}$ of $\mathrm{CS}$ solution, initially (3.7 - 4.1) and adjusted with $1 \mathrm{M} \mathrm{NaOH}$ (4.7 4.8), stirring speed (700 - $1400 \mathrm{rpm})$, reticulation time $(0 \mathrm{~min}-2 \mathrm{~h})$ and surfactant role $(0.5-1.5 \%$ Tween 80) were also studied [3, 13, 21].

The characterization of CSNPS

The particle size (hydrodynamic diameter) and polydispersity index (PDI) were measured by a dynamic light scattering technique (DLS) at $25^{\circ} \mathrm{C}$ using Delsa Nano C Submicron Particle Size Analyzer (Beckman Coulter, Inc., Fullerton, CA).

Statistical analysis

All tests were carried out in triplicate and the results were expressed as mean \pm standard deviation (SD).

\section{Results and Discussion}

The preparation of CSNPs. The influence of different weight ratio between $0.1 \%(\mathrm{w} / \mathrm{v}) \mathrm{CS}\left(\mathrm{CS}_{\mathrm{LMw}}, \mathrm{CS}_{\mathrm{MMw}}\right)$ and $0.1 \%(\mathrm{w} / \mathrm{v})$ TPP on formation of CSNPs, in terms of polydispersity index (PDI) and size of particles is presented in Table I. In these conditions the optimal method $\left(\mathrm{F}_{\mathrm{o}}\right)$ used a stirring speed of $700 \mathrm{rpm}$, for $60 \mathrm{~min}$.

Table I

The characteristics of CSNPs

\begin{tabular}{|c|c|c|c|c|c|c|c|}
\hline \multirow{2}{*}{ Exp. no. } & \multirow{2}{*}{$0.1 \% \mathrm{CS}(\mathrm{mL})$} & \multirow{2}{*}{$\begin{array}{c}0.1 \% \mathrm{TPP} \\
(\mathrm{mL})\end{array}$} & \multirow{2}{*}{$\begin{array}{c}\text { Ratio CS/TPP } \\
(\mathrm{w} / \mathrm{w})\end{array}$} & \multicolumn{2}{|c|}{$\mathrm{CS}_{\mathrm{LMW}}$} & \multicolumn{2}{|c|}{$\mathrm{CS}_{\text {MMW }}$} \\
\hline & & & & PDI value & Size $(\mathrm{nm})$ & PDI value & Size $(\mathrm{nm})$ \\
\hline 1. & 3.0 & 1.0 & $3: 1$ & 0.291 & $231.4 \pm 8.9$ & 0.172 & $\mathrm{NPs}+\mathrm{MPs}$ \\
\hline 2. & 2.5 & 1.5 & $1.66: 1$ & 0.240 & MPs & 0.377 & NPs + MPs \\
\hline 5. & 2.0 & 2.0 & $1: 1$ & & $\mathrm{x}$ & & $\mathrm{x}$ \\
\hline 4. & 1.5 & 2.5 & $1: 1.66$ & & $\mathrm{X}$ & & $\mathrm{X}$ \\
\hline 5. & 1.0 & 3.0 & $1: 3$ & & $\mathrm{x}$ & & $\mathrm{x}$ \\
\hline 6. & 0.5 & 3.5 & $1: 7$ & & $\mathrm{x}$ & & $\mathrm{x}$ \\
\hline
\end{tabular}

$\mathrm{x}=$ precipitation, MPs $=$ microparticles $(>1000 \mathrm{~nm})$

Referring to the $\mathrm{CS}_{\mathrm{LMw}}$, it was observed that the best weight ratio CS/TPP was 3:1, when NPs were obtained with the size $231.4 \pm 8.9 \mathrm{~nm}$. By decreasing the ratio between CS and TPP to 1.66:1, the particles size is increasing to values higher than $700 \mathrm{~nm}$ meaning the MPs were formed. This process could be explained by a lower number of cross-linking sites which has as result an increasing number of CS molecules for one particle formation. The decreasing of CS/TPP ratio (1:1 to $1: 7)$ produces precipitation due to the full cross-linkage of CS. In this case, the decreasing of the surface charge density, and, thus, the lowering of the obtained MPs stability is produced. This behaviour was also reported in the literature by Fan et al. [13].

The optimization of CSNPs formation. In order to establish the optimal parameters, the influence of each one, in the with the constant preservation of the others, regarding the particle size, was analysed and the results are presented in Tables II and III.

Table II

The optimization of $\mathrm{CS}_{\mathrm{LMw}} \mathrm{NPs}$ formation

\begin{tabular}{|c|c|c|c|c|c|c|}
\hline \multirow{2}{*}{$\begin{array}{c}\text { TPP } \\
(\%)\end{array}$} & \multirow{2}{*}{ CS $_{\text {LMw }}(\%)$} & $\begin{array}{c}\text { Ratio CS } \\
\text { LMw } / \text { TPP }\end{array}$ & \multicolumn{2}{|c|}{$\mathrm{pH}=3.7-4.1$} & \multicolumn{2}{c|}{$\mathrm{pH}=4.7-4.8$} \\
\cline { 4 - 7 } & & $(\mathrm{w} / \mathrm{w})$ & PDI value & Size $(\mathrm{nm})$ & PDI value & Size $(\mathrm{nm})$ \\
\hline \multirow{4}{*}{0.1} & 0.050 & $1.5: 1$ & $>0.90$ & $\mathrm{x}$ & 0.503 & MPs \\
\cline { 2 - 7 } & 0.100 & $3: 1$ & 0.204 & $290.1 \pm 9.70$ & 0.151 & $231.4 \pm 8.90$ \\
\cline { 2 - 7 } & 0.133 & $4: 1$ & 0.245 & $403.8 \pm 12.5$ & 0.271 & $342.3 \pm 9.30$ \\
\cline { 2 - 7 } & 0.167 & $5: 1$ & $>0.90$ & MPs & 0.195 & $459.2 \pm 13.6$ \\
\cline { 2 - 7 } & 0.200 & $6: 1$ & $>0.90$ & MPs & 0.303 & $615.9 \pm 9.20$ \\
\hline \multirow{4}{*}{0.15} & 0.050 & $1: 1$ & $>0.90$ & MPs & 0.730 & MPs \\
\cline { 2 - 7 } & 0.100 & $2: 1$ & 0.277 & $343.8 \pm 10.5$ & 0.296 & $280.7 \pm 7.70$ \\
\cline { 2 - 7 } & 0.133 & $2.66: 1$ & 0.303 & $302.6 \pm 9.80$ & 0.281 & $255.7 \pm 12.3$ \\
\cline { 2 - 7 } & 0.167 & $3.34: 1$ & 0.313 & $390.5 \pm 14.1$ & 0.235 & $440.7 \pm 15.6$ \\
\cline { 2 - 7 } & 0.200 & $4: 1$ & 0.293 & $592.2 \pm 12.1$ & 0.299 & $579.8 \pm 13.6$ \\
\hline \multirow{4}{*}{0.2} & 0.050 & $1.5: 2$ & $>0.90$ & MPs & $>0.90$ & MPs \\
\cline { 2 - 7 } & 0.100 & $1.5: 1$ & $>0.90$ & MPs & $>0.90$ & X \\
\cline { 2 - 7 } & 0.133 & $2: 1$ & 0.291 & MPs & 0.583 & MPs \\
\cline { 2 - 7 } & 0.167 & $2.5: 1$ & $>0.9$ & MPs & $>0.90$ & MPs \\
\cline { 2 - 7 } & 0.200 & $3: 1$ & 0.287 & $531.1 \pm 10.7$ & 0.262 & $349 \pm 9.40$ \\
\hline
\end{tabular}

$\mathrm{x}=$ precipitation, MPs $=$ microparticles $(>1000 \mathrm{~nm})$ 
Table III

The optimization of $\mathrm{CS}_{\mathrm{MMW}} \mathrm{NPs}$ formation

\begin{tabular}{|c|c|c|c|c|c|c|}
\hline \multirow{3}{*}{$\begin{array}{l}\text { TPP } \\
(\%)\end{array}$} & \multirow{3}{*}{$\mathrm{CS}_{\text {ммw }}(\%)$} & \multirow{3}{*}{ Ratio CS MMw $/ \mathrm{TPP}(\mathrm{w} / \mathrm{w})$} & \multirow{2}{*}{\multicolumn{2}{|c|}{$\mathrm{pH}=3.7-4.1$}} & \multirow{2}{*}{\multicolumn{2}{|c|}{$\mathrm{pH}=4.7-7.8$}} \\
\hline & & & & & & \\
\hline & & & PDI value & Size $(\mathrm{nm})$ & PDI value & Size $(\mathrm{nm})$ \\
\hline \multirow{5}{*}{0.1} & 0.050 & $1.5: 1$ & 0.245 & $\mathrm{NPs}+\mathrm{MPs}$ & 0.317 & $\mathrm{NPs}+\mathrm{MPs}$ \\
\hline & 0.100 & $3: 1$ & 0.235 & $\mathrm{NPs}+\mathrm{MPs}$ & 0.278 & $251.3 \pm 11.4$ \\
\hline & 0.133 & $4: 1$ & 0.312 & $\mathrm{NPs}+\mathrm{MPs}$ & 0.215 & $385.6 \pm 15.1$ \\
\hline & 0.167 & $5: 1$ & 0.367 & NPs + MPs & 0.311 & MPs \\
\hline & 0.200 & $6: 1$ & 0.652 & $\mathrm{NPs}+\mathrm{MPs}$ & 0.458 & MPs \\
\hline \multirow{5}{*}{0.15} & 0.050 & $1: 1$ & $>0.90$ & MPs & $>0.90$ & MPs \\
\hline & 0.100 & $2: 1$ & 0.266 & NPs + MPs & 0.260 & $282.0 \pm 9.20$ \\
\hline & 0.133 & $2.66: 1$ & 0.224 & NPs + MPs & 0.267 & $477.2 \pm 14.2$ \\
\hline & 0.167 & $3.34: 1$ & 0.258 & NPs + MPs & 0.215 & $524.3 \pm 17.3$ \\
\hline & 0.200 & $4: 1$ & 0.457 & $\mathrm{NPs}+\mathrm{MPs}$ & 0.370 & $\mathrm{NPs}+\mathrm{MPs}$ \\
\hline \multirow{5}{*}{0.2} & 0.050 & $1.5: 2$ & $>0.90$ & MPs & $>0.90$ & $\mathrm{X}$ \\
\hline & 0.100 & $1.5: 1$ & $>0.90$ & $\mathrm{NPs}+\mathrm{MPs}$ & $>0.90$ & MPs \\
\hline & 0.133 & $2: 1$ & 0.224 & NPs + MPs & 0.232 & NPs + MPs \\
\hline & 0.167 & $2.5: 1$ & 0.205 & $\mathrm{NPs}+\mathrm{MPs}$ & 0.249 & $\mathrm{NPs}+\mathrm{MPs}$ \\
\hline & 0.200 & $3: 1$ & 0.365 & $\mathrm{NPs}+\mathrm{MPs}$ & 0.364 & NPs + MPs \\
\hline
\end{tabular}

$\mathrm{x}=$ precipitation, MPs $=$ microparticles $(>1000 \mathrm{~nm})$

The influence of the TPP and CS concentration. Different studies have reported a strong influence of the cross-linking agent (TPP) and CS concentration and their correlation with the hydrodynamic diameter of the obtained particles $[3,13,36]$. In the majority of the experiments, the TPP concentrations of $0.1 \%$ and $0.15 \%$ was correlated with the NPs formation, while increasing the TPP concentration to $0.2 \%$ is associated with the MPs formation. The same behaviour was also observed by Al-Nemrawi et al. [3] and can be explained based on the interactions between the molecules of CS and TPP. Small amounts of TPP are not enough to form a compact matrix with CS and, thus, the CS molecules associate each other and form MPs. Increasing the TPP amount is correlated with an improvement in the cross-linkages CS-TPP and so in the NPs formation, the particles size thus decrease until a critical point. When the TPP exceeds, the CS aggregation occurred, leading to MPs formation. Referring to the influence of the CS concentration, it was noted that the $0.05 \%(\mathrm{w} / \mathrm{v})$ CS was correlated with MPs formation, while an increase of the CS amount was associated with the increase of the NPs size. This process is due to the excess of the CS when several molecules are involved in the formation of a

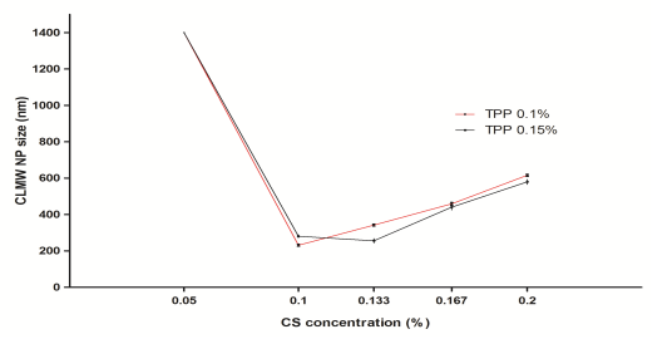

Figure 2.

The influence of different $\mathrm{CS}_{\mathrm{LMW}}$ concentrations on particle size single particle. The most significant example was obtained for $\mathrm{CS}_{\mathrm{LMw}}$ and TPP $(0.1 \%$, w/v), when the particles size ranged from $231.4 \pm 8.9 \mathrm{~nm}(0.1 \%$ $\left.\mathrm{CS}_{\mathrm{LMw}}\right)$ to $615.9 \pm 9.2 \mathrm{~nm}\left(0.2 \% \mathrm{CS}_{\mathrm{LMw}}\right)$.

In the light of the presented data, it was observed that the optimal parameters for NPs formation are: TPP in concentration of $0.1 \%, \mathrm{CS}_{\mathrm{LMW}}$ in concentration of $0.1 \%$ dissolved in acetic acid solution $0.15 \%$ with $\mathrm{pH}$ adjusted at $4.7-4.8, \mathrm{CS} / \mathrm{TPP}$ ratio $=3: 1$, stirring at $700 \mathrm{rpm}$ for $1 \mathrm{~h}$ at room temperature. This formulation was used in further analyses for studying the influence of the other parameters.

The effect of the molecular weight of CS on the formation and the size of the CSNPs was investigated using two types of $\mathrm{CS}\left(\mathrm{CS}_{\mathrm{LMw}}, \mathrm{CS}_{\mathrm{MMW}}\right)$. According to the literature, the increase of molecular weight is associated with the increase of particle size, in the same range of $\mathrm{pH}$ [15]. The results of our experiments (depicted in Tables II and III) support the linear relationship molecular weight-size, generally. The influence of $\mathrm{CS}_{\mathrm{LMW}}$ and $\mathrm{CS}_{\mathrm{MMW}}$ in different concentrations $(0.05 \%, 0.1 \%, 0.133 \%, 0.167 \%, 0.2 \%)$ on particle size, in presence of TPP $(0.1 \%, 0.15 \%)$, is presented in Figures 2 and 3.

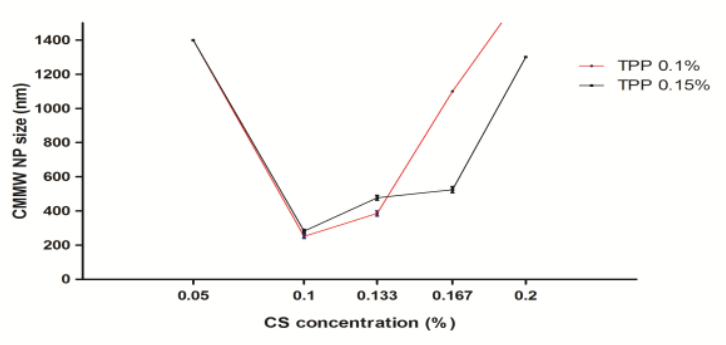

Figure 3.

The influence of different $\mathrm{CS}_{\mathrm{MMW}}$ concentrations on particle size 
The effect of the $\mathrm{pH}$ particle size was investigated for three $\mathrm{pH}$ intervals: $3.7-4.1$ (pH of CS solution), 4.7 - 4.8 (adjusted $\mathrm{pH}$ of $\mathrm{CS}$ solution with $1 \mathrm{M} \mathrm{NaOH}$ ), 4.8 - 7 for optimized formula $\mathrm{F}_{\mathrm{o}}$. It is known that a $\mathrm{pH}$ around 5 can modify the structure of CS and at a $\mathrm{pH}$ higher than 6 the amino groups will be deprotonated, meaning the CS becomes uncharged, and the cross-linkage doesn't occur $[16,30]$. In the same time, CS is soluble in acidic conditions and an increase of $\mathrm{pH}$ to 6 and more is associated with precipitation [6]. The analysis of data (presented in Tables II and III) revealed that the smallest size was obtained for $\mathrm{CS}_{\mathrm{LMW}}$ at $\mathrm{pH}$ of $4.7-4.8$. For $\mathrm{pH}=5.5$, the size of CSNPs was slightly higher $(245 \pm 10.2 \mathrm{~nm})$ and for $\mathrm{pH}=7$ the precipitation was observed.

The effect of the CS/TPP ratio. It was observed that TPP in concentration of $0.2 \%(\mathrm{w} / \mathrm{v})$ was associated, in the most of the cases, with the formation of MPs or mixture of NPs and MPs, while the concentration of $0.1 \%(\mathrm{w} / \mathrm{v})$ conducted to the most efficient crosslinking process. Therefore, the influence of different CS/TPP ratio, ranging between $1: 1(\mathrm{w} / \mathrm{w})$ and $6: 1$ $(\mathrm{w} / \mathrm{w})$, on the particles size at $\mathrm{pH}=4.7-4.8$ was investigated. The best NPs were obtained using CS and TPP in concentration of $0.1 \%$ and CS/TPP ratio of 3:1 (CS $\left.\mathrm{CMw}_{\mathrm{LM}}-231.4 \pm 8.9 \mathrm{~nm}, \mathrm{CS}_{\mathrm{MMw}}-251.3 \pm 11.4 \mathrm{~nm}\right)$. The increase of CS/TPP ratio to 4:1 was associated with a higher particle size, depending on CS, TPP, and as well as on CS molecular weight, as follow: $\mathrm{CS}_{\mathrm{LMW}}-342.3 \pm 9.3 \mathrm{~nm}$ to $579.8 \pm 13.6 \mathrm{~nm}$, $\mathrm{CS}_{\mathrm{MMW}}-385.6 \pm 15.1 \mathrm{~nm}$ to a mixture of NPs and MPs (Tables II and III). It was noted the critical role of CS/TPP ratio for the formation of NPs using both types of $\mathrm{CS}\left(\mathrm{CS}_{\mathrm{LMw}}, \mathrm{CS}_{\mathrm{MMW}}\right)$. In case of $\mathrm{CS}_{\mathrm{LMw}}$, only the CS/TPP ratio of 1.1 and $1.5 / 1$ were associated with the MPs formation, while in the case of $\mathrm{CS}_{\mathrm{MMW}}$ the NPs are produced when CS/TPP ratio ranged between $2 / 1$ and 4/1.

This behaviour is similar with that reported by Gan et al. and Koukaras et al. who found the optimal CS/ TPP ratio 4/1. The differences could be attributed to the differences in molecular weight or deacetylation degree of the CS $[15,21]$.

When the concentration of CS decreases, that means the CS/TPP ratio also minimizes in the critical point, the interactions between the CS decrease, which led to an increase of the cross-linkages between the TPP and the CS [13]. The increase of CS/TPP ratio will be associated with the of MPs formation.

The effect of the reticulation time. The results revealed that the particle size decreases from $0 \mathrm{~min}$ to the critical point of $1 \mathrm{~h}$, after which an aggregation was observed (Figure 4).

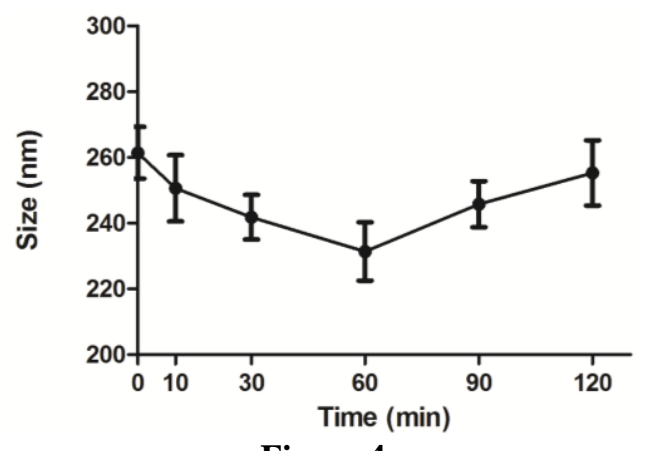

Figure 4.

The effect of the reticulation time on the NPs size

The effect of the surfactant agent. The surfactants, known as coating agents, are often used to avoid the particle aggregation due to their high effect on the dispersion. These substances decrease the interfacial tension between materials and the pressure between the outside and the inside of the particle, and so reduce the size particle [27]. For example, the Poloxamer 188 , a polymer with amphiphilic structure, was used to develop new CSNPs loaded with rosuvastatin calcium by ionotropic gelation method [35]. Tween 80 , called also Polysorbate 80 , is a common non-ionic compound, with amphiphilic properties, characterized by biodegradability and cellular non-toxicity at low concentrations. It is used as coating agent for NPs and to improve the drug-targeted delivery, leading to an improved biological effect [38]. Tween 80 acts as stabilizing agent $[23,26]$, its effect on particle size being dependent on the concentration [6].

In this study, the influence of the Tween 80, in different concentrations (v/v), on particle size was investigated. Tween $80(0.5 \%, 1 \%, 1.5 \%)$ was added to $0.1 \%$ CSLMW and the mixture was stirred for 30 min, after which the TPP was added. The results noted a bimodal distribution of the CSNPs when the surfactant agent was added, as shown in Table IV. The analysis of the results highlighted that the first population of particles was formed only between CSLMW and Tween 80 , the increase of Tween 80 concentration from $0.5 \%$ to $1.5 \%(\mathrm{v} / \mathrm{v})$ being associated with slightly increasing of the particles size $(10.1 \mathrm{~nm}-13.1 \mathrm{~nm})$. When TPP was added the second population of particles was formed by ionic gelation. The study showed that Tween 80 was absorbed to the CSNPs surface, leading to slightly larger particles $(273 \pm 13.2 \mathrm{~nm}-299.2 \pm$ $11.5 \mathrm{~nm}$ ) depending to the concentration, and lower dispersity due to the PDI value increasing from 0.345 to 0.381 . 
The effect of the Tween 80 concentration on CSNPs formation

\begin{tabular}{|c|c|c|c|}
\hline Tween 80 concentration $(\%)$ & $1^{\text {st }}$ population size $(\mathrm{nm})$ & $2^{\text {nd }}$ population size $(\mathrm{nm})$ & PDI value \\
\hline 0 & - & $231.4 \pm 8.9$ & 0.291 \\
\hline 0.5 & 10.1 & $273.0 \pm 13.2$ & 0.345 \\
\hline 1.0 & 10.3 & $280.0 \pm 10.6$ & 0.372 \\
\hline 1.5 & 13.1 & $299.2 \pm 11.5$ & 0.384 \\
\hline
\end{tabular}

The stability in time of NPs can be affected by different variables, such as the concentration and the $\mathrm{pH}$ of the solutions or the room temperature. The stability of CSNPs synthesized according to the optimized procedure $\left(\mathrm{F}_{\mathrm{o}}\right)$, in terms of particle size, was analysed during $48 \mathrm{~h}$ at constant room temperature. The hydrodynamic particle size was measured at different time intervals: $0 \mathrm{~min}, 12 \mathrm{~h}, 24 \mathrm{~h}, 36 \mathrm{~h}$ and $48 \mathrm{~h}$ (Figure 5). It was observed only a slight increase of CSNPs size over time, without the appearance of any aggregates, as previously reported by Gan et al. [15].

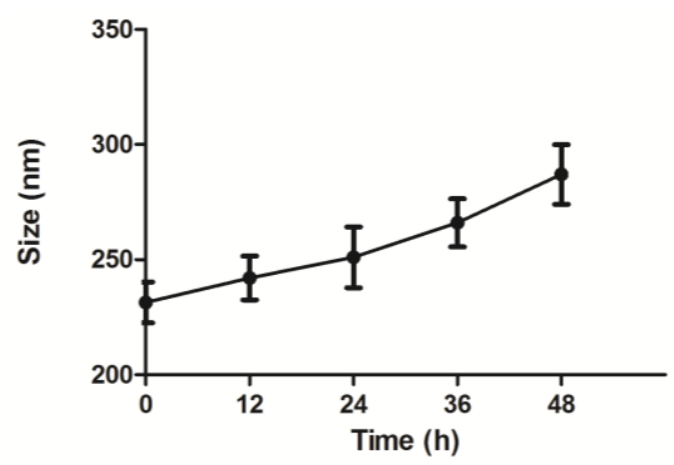

Figure 5.

The stability of CSNPs (particle size) during $48 \mathrm{~h}$

The effect of the stirring speed. It is known that the stirring speed is an important parameter which influences the particle size and stability or drug loading [23].

The results showed that the increase of the speed from $700 \mathrm{rpm}$ to $1000 \mathrm{rpm}$ was associated with a reducing of the CSNPs size from $231.4 \pm 8.9 \mathrm{~nm}$ to $208.8 \pm 8.5 \mathrm{~nm}$ and also with a decreasing of PDI value from 0.291 to 0.151 (Table V).

Table V

The stirring speed effect on $\mathrm{CS}_{\mathrm{LMw}}$ particles size

\begin{tabular}{|c|c|c|}
\hline \multirow{2}{*}{ Stirring speed (rpm) } & \multicolumn{2}{|c|}{ CS $_{\text {LMW }}$} \\
\cline { 2 - 3 } & PDI value & Size $(\mathrm{nm})$ \\
\hline 700 & 0.291 & $231.4 \pm 8.9$ \\
\hline 850 & 0.275 & $226.9 \pm 7.6$ \\
\hline 1000 & 0.151 & $208.8 \pm 8.5$ \\
\hline 1150 & 0.138 & Bimodal \\
\hline 1300 & 0.149 & NPs + MPs \\
\hline 1400 & 0.141 & NPs + MPs \\
\hline
\end{tabular}

MPs = microparticles

This behaviour is according to the literature [23] and can be explained by the increase of the TPP dispersion in the CS solution due to the accelerated shear forces which lead, finally, to a particle size reducing and a monodispersity [3]. It was observed that a higher stirring (1150 rpm - $1400 \mathrm{rpm}$ ) triggered the aggregation of the particles with the formation of MPs due to the lower surface charge of the particles and to the lower repulsion energy between them [13].

\section{Conclusions}

In this study CSNPs were synthesized using the ionic gelation method and the influence of several factors such as CS and TPP concentration, $\mathrm{pH}$ of CS solution, stirring speed and reticulation time, on cross-linking process were investigated. The optimized CSNPs with size of $208.8 \pm 8.5 \mathrm{~nm}$ were obtained using the following parameters: $0.1 \% \mathrm{CS}_{\mathrm{LMW}}(\mathrm{pH}=4.7-4.8)$, $0.1 \% \mathrm{TPP}$, stirring for $1 \mathrm{~h}$ at $1000 \mathrm{rpm}$. Based on this optimized method, the synthesized CSNPs will be used in the next applications, as drug delivery systems for antidiabetic and anti-inflammatory drugs.

\section{Acknowledgement}

Scientific research funded by "Grigore T. Popa" University of Medicine and Pharmacy Iași, based on contracts no. 23401/07.11.2018 and 30341/28.12.2017.

\section{References}

1. Ahmadi F, Oveisi Z, Samani SM, Amoozgar Z, Chitosan based hydrogels: characteristics and pharmaceutical applications. Res Pharm Sci., 2015; 10(1): 1-16.

2. Ajdnik U, Zemljič L, Bračič M, Maver U, Plohl O, Rebol J, Functionalisation of silicone by drug-embedded chitosan nanoparticles for potential applications in otorhinolaryngology. Materials, 2019; 12: 1-20.

3. Al-Nemrawi NK, Alsharif SSM, Dave RH, Preparation of chitosan-tpp nanoparticles: The influence of chitosan polymeric properties and formulation variables. Int J App Pharm., 2018; 10(5): 60-65.

4. Al-Rashed MM, Niknezhad S, Jana SC, Mechanism and factors influencing formation and stability of chitosan/lignosulfonate nanoparticles. Macromol Chem Phys., 2019; 220: 1-8.

5. Anand M, Sathyapriya P, Maruthupandy M, Hameedha Beevi A, Synthesis of chitosan nanoparticles by TPP and their potential mosquito larvicidal application. Front Lab Med., 2018; 2(2): 72-78.

6. Asasutjarit R, Sorrachaitawatwong C, Tipchuwong N, Pouthai S, Effect of Formulation Compositions on Particle Size and Zeta Potential of Diclofenac SodiumLoaded Chitosan Nanoparticles. Int J Pharm Pharm Sci., 2013; 7(9): 568-570.

7. Avram I, Lupaşcu FG, Confederat L, Constantin SM, Stan CI, Profire L, Chitosan microparticles loaded with 
antidiabetic drugs - Preparation and characterization. Farmacia, 2017; 65(3): 443-448.

8. Bhattarai N, Gunn J, Zhang M, Chitosan-based hydrogels for controlled, localized drug delivery. Adv Drug Deliv Rev., 2010; 62: 83-99.

9. Bosquez-Molina E, Zavaleta-Mejía L. New bioactive biomaterials based on chitosan. In Chitosan in the preservation of agricultural commodities. Cambridge: Academic Press, 2016.

10. Choi C, Nam JP, Nah JW, Application of chitosan and chitosan derivatives as biomaterials. $J$ Ind Eng Chem., 2016; 33: 1-10.

11. Constantin SM, Buron F, Routier S, Vasincu IM, Apotrosoaei M, Lupascu F, Confederat L, Tuchilus C, Constantin MT, Sava A, Profire L, Formulation and characterization of new polymeric systems based on chitosan and xanthine derivatives with thiazolidin4-one scaffold. Materials, 2019; 12: 1-19.

12. das Neves J, Bahia MF, Amiji MM, Sarmento B, Mucoadhesive nanomedicines: characterization and modulation of mucoadhesion at the nanoscale. Exp Opin Drug Deliv., 2011; 8(8): 1085-1104.

13. Fan W, Yan W, Xu Z, Ni H, Formation mechanism of monodisperse, low molecular weight chitosan nanoparticles by ionic gelation techniq. Colloids Surf B Biointerfaces, 2012; 90: 21-27.

14. Francolini I, Perugini E, Silvestro I, Lopreiato M, Scotto d'Abusco A, Valentini F, Placidi E, Arciprete F, Martinelli A, Piozzi A, Graphene oxide oxygen content affects physical and biological properties of scaffolds based on chitosan/graphene oxide conjugates. Materials, 2019; 12: 1-17.

15. Gan Q, Wang T, Cochrane C, Mccarron P, Modulation of surface charge, particle size and morphological properties of chitosan - TPP nanoparticles intended for gene delivery. Colloids Surf B Biointerfaces, 2005; 44: 65-73.

16. Gao W, Chan JM, Farokhzad OC, pH-Responsive nanoparticles for drug delivery. Mol Pharm., 2010; 7(6): 1913-1920.

17. Goyal R, Macri LK, Kaplan HM, Kohn J, Nanoparticles and nanofibers for topical drug delivery. J Control Release, 2016; 240: 77-92.

18. Gronczewska E, Defort A, Kozio JJ, Kinetics of ibuprofen release from magnetic nanoparticles coated with chitosan, peg and dextran. Pharm Chem J., 2016; 50(7): 491-499.

19. Gupta R, Diabetes treatment by nanotechnology. $J$ Biotechnol Biomater., 2017; 7: 1-2.

20. Khezri A, Karimi A, Yazdian F, Jokar M, Rezazadeh S, Rashedi H, Tavakoli Z, Molecular dynamic of curcumin/chitosan interaction using a computational molecular approach: Emphasis on biofilm reduction. Int J Biol Macromol., 2018; 114: 972-978.

21. Koukaras EN, Papadimitriou A, Bikiaris DN, Froudakis GE, Insight on the formation of chitosan nanoparticles through ionotropic gelation with tripolyphosphate. Mol Pharm., 2012; 9: 2856-2862.

22. López-león T, Carvalho ELS, Seijo B, Ortega-Vinuesa JL, Bastos-gonzález D, Physicochemical characterization of chitosan nanoparticles: electrokinetic and stability behavior. J Colloid Interface Sci., 2005; 283: 344-351.
23. Lupaşcu F, Dragostin O, Confederat L, Dubruel P, Dash M, Keshari S, Panzariu A, Vasincu I, Profire L, Optimized method for obtaining chitosan nanoparticles loaded with xanthine derivative. Med-Surg J., 2015; 119(3): 925-930.

24. Lupaşcu FG, Avram I, Confederat L, Constantin SM, Stan CI, Lupuşoru EC, Sava A, Profire L, Biological evaluation of chitosan-antidiabetic drug formulations for the treatment of diabetes mellitus. Farmacia, 2017; 65(4): 508-514.

25. Luque-Alcaraz AG, Lizardi-Mendoza J, Goycoolea FM, Higuera-Ciapara I, Argüelles-Monal W, Preparation of chitosan nanoparticles by nanoprecipitation and their ability as a drug nanocarrier. RSC Advances, 2016; 6: 59250-59256.

26. Mofazzal Jahromi MA, Al-Musawi S, Pirestani M, Fasihi Ramandi M, Ahmadi K, Rajayi H, Mohammad Hassan Z, Kamali M, Mirnejad R, Curcumin-loaded chitosan tripolyphosphate nanoparticles as a safe, natural and effective antibiotic inhibits the infection of Staphylococcus aureus and Pseudomonas aeruginosa in vivo. Iran J Biotech., 2014; 12(3): 1-8.

27. Morsy SMI, Role of surfactants in nanotechnology and their applications. Int J Curr Microbiol App Sci., 2014; 3(5): 237-260.

28. Muţ AM, Vlaia L, Coneac G, Olariu I, Vlaia V, Popoiu C, Hîrjău M, Lupuliasa D, Novel topical chitosan/hydroxypropylmethylcellulose - Based hydrogels containing fluconazole and sucrose esters. Formulation, physicochemical characterization, in vitro drug release and permeation. Farmacia, 2018; 66(1): 59-69.

29. Muţ AM, Vlaia L, Coneac G, Olariu I, Vlaia V, Stănciulescu C, Mitu MA, Szabadai Z, Lupuliasa D, Chitosan/HPMC-based hydrogels containing essential oils for topical delivery of fluconazole: Preliminary studies. Farmacia, 2018; 66(2): 248-256.

30. Nilsen-Nygaard J, Strand SP, Vårum KM, Draget KI, Nordgård CT, Chitosan: Gels and interfacial properties. Polymers, 2015; 7: 552-579.

31. Oh JW, Chun SC, Chandrasekaran M, Preparation and in vitro characterization of chitosan nanoparticles and their broad-spectrum antifungal action compared to antibacterial activities against phytopathogens of tomato. Agronomy, 2019; 9: 1-12.

32. Onishi H, Chitosan microparticles. J Drug Del Sci Tech., 2010; 20(1): 15-22.

33. Pathak S, Hosseinkhani H, Recent trends in diabetes treatment using nanotechnology. Dig J Nanomater Bios., 2016; 7(1): 85-95.

34. Pham TT, Nguyen TH, Thi TV, Nguyen T-T, Le TD, Vo DMH, Nguyen DH, Nguyen CK, Nguyen DC, Nguyen TT, Bach LG, Investigation of chitosan nanoparticles loaded with protocatechuic acid (PCA) for the resistance of Pyricularia oryzae fungus against rice blast. Polymers, 2019; 11: 1-10.

35. Ponnuraj R, Janakiraman K, Gopalakrishnan S, Jeyakumar HJ, Venkateswarlu V, Narayanan DS, Formulation and characterization of rosuvastatin calcium nanoparticles. Indo Am J Pharm Res., 2015; 5(2): 767-779.

36. Sreekumar S, Goycoolea FM, Moerschbacher BM, Rivera-Rodriguez GR, Parameters influencing the 
size of chitosan-TPP nano- and microparticles. Sci Rep., 2018; 8: 1-11.

37. Xie J, Li A, Li J, Advances in $\mathrm{pH}-$ Sensitive polymers for smart insulin delivery. Macromol Rapid Commun., 2017; 38: 1-14.

38. Tao X, Li Y, Hu Q, Zhu L, Huang Z, Yi J, Yang X, $\mathrm{Hu}$ J, Feng X, Preparation and drug release study of novel nanopharmaceuticals with polysorbate 80 surface adsorption. J Nanomat., 2018; 2018: 1-12.

39. Zhang H, Oh M, Allen C, Kumacheva E, Monodisperse chitosan nanoparticles for mucosal drug delivery. Biomacromolecules, 2004; 5: 2461-2468. 